\title{
Study of hospitalization and mortality in Korean diabetic patients using the diabetes complications severity index
}

\author{
Hyunju Yoo, Eunjung Choo and Sukhyang Lee* (1)
}

\begin{abstract}
Background: The prevalence of type 2 diabetes mellitus (T2DM) is expected to increase from $7.7 \%$ in 2017 to $8.4 \%$ in 2045 worldwide. Diabetes complications contribute to morbidity and mortality. To evaluate whether the diabetes complications severity index (DCSI) was associated with increased risks of mortality and hospitalization.

Methods: A retrospective cohort study was conducted using the National Health Insurance Database (NHID) sample cohort of 1,102,047 patients (2002-2015) in Korea. Diabetes complications were evaluated at 2 years after the initial diagnosis and during the subsequent follow-up period (mean duration $6.56 \pm 2.81$ years). The type and severity of complications were evaluated on the basis of the International Classification of Disease Ninth (ICD-9) codes used in DCSI with 7 categories and 55 subcategories of complications. The Cox proportional hazard and Poisson regression models were used to evaluate the mortality and hospitalization rates. The incidence and relative risk of diabetes complications as well as the risk of mortality and hospitalization were the main outcome measures.

Results: A total of 27,871 patients were finally included and grouped by the number of complications present at 2 years. Four hundred ninety patients (5.37\%) died without complications, 659 (7.31\%) died with one complication and $1153(11.85 \%)$ died with two or more complications. As DCSI at index date increased, the risk of additional new diabetes complications increased by $26 \%$ [relative risk (RR) 1.26, 95\% Cl 1.25-1.27]. The risks of mortality and hospitalization were linearly related to DCSI [hazard ratio 1.13 (95\% Cl 1.11-1.16), relative risk 1.04 (95\% Cl 1.03-1.06)].
\end{abstract}

Conclusions: Patients with higher incidence and severity of diabetes complications have increased risks of mortality and hospitalization.

Keywords: Diabetes mellitus, National Health Insurance Database, Diabetes complications, Korea

\section{Background}

The prevalence of type 2 diabetes mellitus (T2DM) is expected to rise from $7.7 \%$ in 2017 to $8.4 \%$ in 2045 worldwide. The number of deaths due to diabetes was estimated to be 5 million, accounting for $9.9 \%$ of the total number of deaths worldwide in 2017 [1, 2].

Diabetic complications could be identified at the time of DM diagnosis with pathophysiological changes ever

\footnotetext{
* Correspondence: suklee@ajou.ac.kr

Division of Clinical Pharmacy, College of Pharmacy, Ajou University, 206 Worldcup-ro Yeongtong-gu, Suwon 16499, South Korea
}

since the stage of prediabetes. Di Pino et al. reported that the glycated hemoglobin $\mathrm{A}_{1 \mathrm{C}}\left(\mathrm{HbA}_{1 \mathrm{C}}\right)$ and receptors for advanced glycation end products (RAGEs) were related to cardiovascular disease in subjects with prediabetes based on the impaired fasting glucose or glucose tolerance test. Previous studies showed the association of the glycation and inflammation with morbidity and mortality in T2DM [3-6]. The goal of diabetes treatment is not only to maintain an optimal blood glucose level but also to prevent DM complications, such as nephropathy, neuropathy, retinopathy, and

(c) The Author(s). 2020 Open Access This article is licensed under a Creative Commons Attribution 4.0 International License, which permits use, sharing, adaptation, distribution and reproduction in any medium or format, as long as you give appropriate credit to the original author(s) and the source, provide a link to the Creative Commons licence, and indicate if changes were made. The images or other third party material in this article are included in the article's Creative Commons licence, unless indicated otherwise in a credit line to the material. If material is not included in the article's Creative Commons licence and your intended use is not permitted by statutory regulation or exceeds the permitted use, you will need to obtain permission directly from the copyright holder. To view a copy of this licence, visit http://creativecommons.org/licenses/by/4.0/ The Creative Commons Public Domain Dedication waiver (http://creativecommons.org/publicdomain/zero/1.0/) applies to the data made available in this article, unless otherwise stated in a credit line to the data. 
cardiocerebrovascular disease [7-9]. The 10-year risk of cardiovascular disease (CVD 10-year risk) was used as an index to evaluate the risk of developing CVD, which included age, male, DM, hypertension, and dyslipidemia as risk factors [10-12]. T2DM is an independent risk factor that increases the risk of CVD by approximately 2 fold and CVDs are the leading cause of deaths in diabetic patients [13]. Diabetic nephropathy is the most common complication that occurs in $20-40 \%$ of diabetic patients and progresses to end-stage renal failure requiring dialysis or kidney transplantation. In the case of neuropathy, symptoms are very diverse, and blood glucose control can delay but not prevent nerve damage. Diabetic retinopathy is a common cause of blindness and is closely related to the duration of diabetes and failure to control blood glucose levels [9]. The medical cost, mortality, and disease burden of DM increase as the number of complications increases [14-16].

A study using data from patients with diabetes at nine primary care clinics reported the diabetes complications severity index (DCSI), which reflects the severity of the complications, and identified an association of the frequency and severity of diabetes complications with the risks of mortality and hospitalization; DCSI was demonstrated to be a good indicator of the association between diabetes complications and mortality [14]. Rosenzweig et al. reported the use of DCSI for evaluation of healthcare costs and the management of comorbidities in patients with diabetes. The medical costs were 10 times higher for diabetic patients in the very high-risk group than in the low-risk group [17]. Several studies have evaluated the risk of diabetes complications using the real world data of diabetic patients. Selby et al. developed a prediction rule to identify high-risk factors associated with diabetes complications using the large clinical database of Kaiser Permanente. They found that a history of complications was the strongest risk factor for the incidence of diabetes complications [18]. Clinical significance of DCSI needs to be assessed in usefulness for evaluating the risks of mortality and hospitalization using the real world big data in a Korean population.

\section{Methods}

\section{Aim of the study}

This retrospective cohort study aimed to investigate whether diabetes complications severity index (DCSI) is associated with all-cause mortality and hospitalization rates in patients with $\mathrm{T} 2 \mathrm{DM}$ in a Korean population. DCSI was based on the frequency and pattern of complications in diabetic patients at 2 years after T2DM diagnosis. Also, we analyzed factors that may affect newly developed complications beyond 2 years from the initial diagnosis.

\section{Design and setting of the study}

A retrospective cohort study was conducted using the Korean National Health Insurance Service-National Sample Cohort (NHIS-NSC) 2.0 which was a population-based database with 1,102,047 patients (2002-2015). The NHIS cohort 2.0 comprises the insurance claim database of approximately 1 million individuals, accounting for $2 \%$ of the Korean population who retained the status of health insurance members and medical entitlement. This sample cohort was selected by stratified random sampling according to sex, age, eligibility status, and income levels to represent the Korean population that comprised nearly 50 million individuals. They were followed up for 14 years unless an individual's eligibility was disqualified due to death or emigration. The insurance claim database comprised information on demographic and clinical characteristics and medical record data, including age; sex; dates of birth and death; clinic, hospital, and pharmacy visit information; disease diagnosis; medical care procedures; and prescribed medications. The database comprises five tables that provide information on the qualification of insurance, birth and death, medical care, health examination, medical institutions, and duration of hospitalization. The death of the subject is linked to the cause of death at the National Statistical Office to identify the date and cause of death. Before the study, individual information in the NHISNSC database was de-identified to protect the patients' privacy, and patients in the database only had encrypted identification numbers $[19,20]$.

The enrollment date was defined as the date of diabetic diagnosis and diabetes medication. The index date was defined as 2 years after the diagnosis of diabetes. The prediagnosis and postdiagnosis period were 2 years before and after the diagnosis of diabetes, respectively. The follow-up period, from the index date to 2015, was used to assess the complications, deaths, and hospitalizations that occurred during this period (Fig. 1).

Data regarding demographic characteristics, comorbidities, concomitant medications, and clinical procedures were collected. Comorbidities before the index date were identified, and the Charlson comorbidity index (CCI) score was calculated for the postdiagnosis period [21]. The concomitant medications used in the postdiagnosis period were aspirin, cilostazol, sarpogrelate, angiotensin-1 converting enzyme inhibitor or angiotensin-2 receptor blocker (ACEI/ARBs), dihydropyridine calcium channel blocker (DHP-CCB), and statin. Antidiabetic drug adherence was evaluated in patients with a medication possession rate (MPR), which was defined as the ratio (A/B) of the total prescription days (A) to the duration from the first to the last date of drug use during the postdiagnosis period (B). 


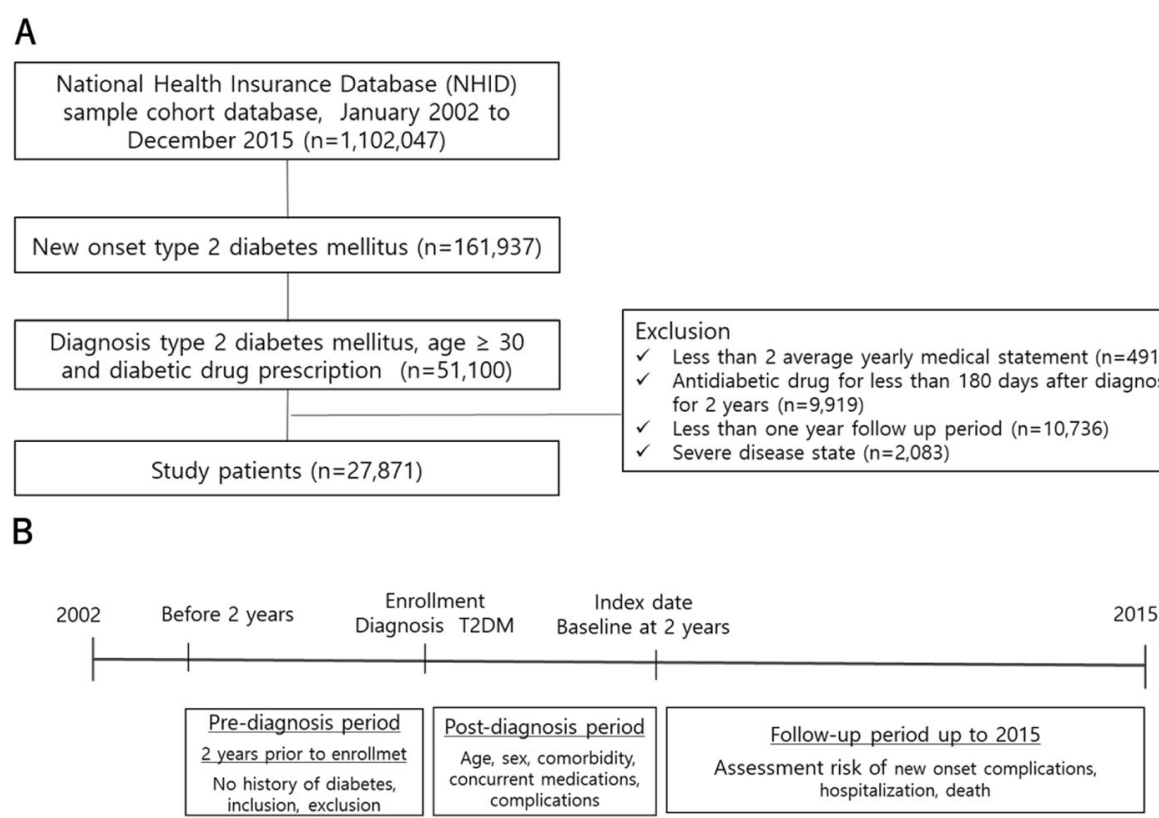

Fig. 1 Flow chart of the study population (a) and schematic description of the study design (b)

\section{Inclusion and exclusion criteria}

The inclusion criteria in this study were patients aged $\geq 30$ years who were diagnosed with T2DM (E11.0) and claim data for prescriptions of antidiabetic medication for 180 days or longer. The initial diagnosis of diabetes was defined as newly diagnosed patients for 2 years before enrollment in the study. Patients included when they had a diagnosis of diabetes mellitus, prescription of diabetes medications, and medical insurance claim records more than twice a year.

The exclusion criteria were patients with chronic kidney disease stage 5 (ICD-10 codes, N18.5), extracorporeal dialysis (ICD-10 codes, Z49.1), other dialysis (ICD-10 codes, Z49.2), kidney transplant status (ICD-10 Z94.0), liver dysfunction (ICD-10 codes, K72.1), and cancer (ICD-10 codes, C00-C80). Patients with end-stage diseases were excluded to reduce bias from the incidence of complications, hospitalization, and deaths due to underlying diseases other than diabetes. Patients were excluded if they took antidiabetic drugs for less than 180 days and died before the index date during the 2-year postdiagnosis period.

\section{Outcomes}

The type and frequency of diabetes complications were analyzed at the index date of 2 years after T2DM diagnosis (baseline) and during the follow-up period. Diabetes complications were grouped into 7 categories (nephropathy, neuropathy, retinopathy, cerebrovascular disease, cardiovascular disease, peripheral vascular disorder, and metabolic diseases) and 55 subcategories. The trends of changes in the complications were evaluated from the index date to the end of the follow-up period. Complications were also analyzed using DCSI that reflected the influence of diabetes complications. DCSI was based on a scale ranging from 0 to 2 for each complication abnormality, with a total maximum score of 13 (Supplement Table 1).

New onset complications were defined as the appearance of new diagnostic codes for complications in the DCSI category or subcategories during subsequent periods. These were new diagnostic codes for complications that did not occur before the index date. The pattern of drug use was evaluated in patients with or without new-onset complications. The use of medication for $\geq 90$ days was evaluated for 1 year before the index date. The occurrence of complications was evaluated to identify its association with age, sex, comorbidity, the type of antidiabetics [metformin, sulfonylurea (SU), dipeptidyl peptidase-4 inhibitor (DPP4I), $\alpha$-glucosidase inhibitor, thiazolidinedione, and insulin], the pattern of pharmacotherapy (monotherapy or dual combination therapy), and concomitant medications (Supplement Table 2).

The mortality and the frequency and duration of hospitalization due to all causes were analyzed in patients with none, one, or two or more complications during the follow-up period. The association of hospitalization and mortality with age, sex, insulin use, number of complications, and DCSI was evaluated during the follow-up period. The survival analysis of the patients was performed on the basis of the number of 
complications at baseline during the follow-up period. Receiver operating characteristics analysis was performed to determine the usefulness of DCSI in evaluating the association of diabetes complications with mortality.

\section{Statistical analyses}

The baseline characteristics were expressed as mean \pm standard deviation (or median and interquartile range) for continuous variables and as the frequency with percentages for categorical variables, as applicable. The continuous variables were compared using Student's t-test or one-way analysis of variance, and the categorical variables were compared using the chi-squared test. Poisson regression models were used to evaluate the new-onset diabetes complications and hospitalizations. The Kaplan-Meier method and log-rank test were used to evaluate the mortality according to the number of diabetes complications, and the Cox proportional hazard model was used to predict mortality. The risk of hospitalization or mortality in diabetic patients was analyzed by adjusting the covariates to account of effect age, sex, and insulin use.

\section{Results}

\section{Characteristics of the study population}

A total of 161,937 patients with new diagnosis T2DM at enrollment were selected from the NHIS database. Among them, 51,100 patients were identified on the basis of inclusion criteria aged $\geq 30$ years with a prescription for antidiabetic medications. Further, 23,229 patients were excluded on the basis of the following exclusion criteria: less than 2 insurance claims each year ( $n=491$ patients), took antidiabetic drugs for less than 180 days ( $n=9919$ patients), and the presence of an end-stage disease ( $n=2083$ patients) (Fig. 1).

The final study population comprised 27,871 patients; their mean age was 57.28 years, $54.29 \%$ men and $45.71 \%$ women, and the mean duration of follow up was $6.56 \pm$ 2.81 years. The major concomitant diseases were hypertension in $66.94 \%$ and dyslipidemia in $72.57 \%$ of patients. During the 2-year postdiagnosis period, $70.06 \%$ of the patients had taken metformin, 53.62\% SU, 15.48\% DPP4I, and 2.57\% insulin. The adherence of antidiabetic drugs was $77.86 \%$ measured as medication possession rate. The concomitant medication was ACEI/ARB in $47.81 \%$ of the patients, DHP-CCB in $40.67 \%$, and statin in $46.52 \%$. Of 27,871 patients, 9130 patients (32.76\%) had no complication, 9015 patients $(32.35 \%)$ had one, and $9726(34.90 \%)$ patients had two or more complications at the index date of 2 years postdiagnosis. Older patients were found to have more complications than younger patients. The CCI score for coexisting diseases was $1.66 \pm 1.00$ in patients with no complication, $2.62 \pm$
1.35 in patients with one, and $4.12 \pm 1.82$ in patients with two or more complications (Table 1).

Total diabetes complications at 2 years postdiagnosis and during the follow-up period

The number of patients with complications at the index date the 2-year postdiagnosis period was total 18,741. Patients with no complication were $9130(32.76 \%)$ at index date and 3714 (13.33\%) during the follow-up period; patients with one complication was 9015 (48.10\%) and 5888 (24.37\%) during the same periods, respectively. Two or more complications were observed in $9726(34.89 \%)$ and $18,269(65.54 \%)$ patients during the same periods, respectively. Complications at the index date were the highest for neuropathy in 8896 (47.47\%) followed by cardiovascular complications in 7508 (40.06\%) and retinopathy in 5739 (30.62\%). Patients with complications at the end of follow-up period were 24 , 157 of 27,871 (86.67\%) with the highest for neuropathy in $15,385(63.69 \%)$, followed by cardiovascular complications in 12,652 (52.37\%) and retinopathy in 11,698 (48.42\%) of 24,157 patients (Supplement figure 1, Supplement Table 3).

\section{Incidence and relative risk of new-onset diabetes} complications during the follow-up period

New additional complications not present at baseline developed in 18,741 of $27,871(67.14 \%)$ patients during the follow-up period with the highest for neuropathy 9913 (54.05\%), followed by cardiovascular complications 7738 (42.19\%) and retinopathy 7595 (41.41\%) out of 18,741 patients (Table 2).

The risk of new complications during the follow-up period increased with age, female, and a higher CCI score. As DCSI at index date increased, the risk of new complications increased by $26 \%$ [relative risk (RR) 1.26 , 95\% CI 1.25-1.27]. As expected the use of more than three antidiabetics was associated with the risk of new complications by $13 \%$ increase (RR 1.13, 95\% CI 1.101.17); the risk was relatively higher in patients treated with insulin (RR 1.07, 95\% CI 1.03-1.11) and relatively lower in patients treated with statins (RR 0.71, 95\% CI 0.69-0.73) as the concomitant medication. On comparing several monotherapies of antidiabetic drugs with reference metformin, the risk of new complications was higher in patients treated with sulfonylurea (RR 1.29, 95\% CI 1.27-1.32) than with DPP4-I (RR 0.77, 95\% CI 0.70-0.85). On comparing dual therapy [metformin + SU, MS] with [metformin + DPP4-I, MD], patients treated with MD had a 29\% (RR 0.71, 95\% CI 0.69-0.73) lower risk of new complications (Table 3). 
Table 1 Baseline characteristics at 2 years after T2DM diagnosis

\begin{tabular}{|c|c|c|c|c|}
\hline \multirow[t]{2}{*}{ Characteristics } & \multirow{2}{*}{$\begin{array}{l}\text { All subjects } \\
(27,871)\end{array}$} & \multicolumn{3}{|c|}{ Number of complications } \\
\hline & & None (9130) & 1 (9015) & $\geq 2$ (9726) \\
\hline \multicolumn{5}{|l|}{ Age (year) } \\
\hline Mean \pm SD & $57.28 \pm 11.97$ & $54.30 \pm 11.42$ & $57.05 \pm 11.87$ & $60.30 \pm 11.84$ \\
\hline Median, IQR & $57,48-66$ & $53,46-62$ & $56,48-66$ & $61,52-69$ \\
\hline$<65$ & $19,643(70.48)$ & $7327(80.25)$ & $6448(71.53)$ & $5868(60.33)$ \\
\hline$\geq 65$ & $8228(29.52)$ & $1803(19.75)$ & $2567(29.47)$ & $3858(39.67)$ \\
\hline \multicolumn{5}{|l|}{ Gender, n (\%) } \\
\hline Men & $15,132(54.29)$ & $5526(60.53)$ & $4930(54.69)$ & $4676(48.08)$ \\
\hline Women & $12,639(45.71)$ & $3604(39.47)$ & $4085(45.31)$ & $5050(51.92)$ \\
\hline $\mathrm{CCl}$, mean $\pm \mathrm{SD}$ & $2.83 \pm 1.77$ & $1.66 \pm 1.00$ & $2.62 \pm 1.35$ & $4.12 \pm 1.82$ \\
\hline Follow up period, year \pm SD & $6.56 \pm 2.81$ & $6.61 \pm 2.86$ & $6.56 \pm 2.80$ & $6.52 \pm 2.77$ \\
\hline Median, IQR & $6.3,4.1-9.0$ & $6.3,4.1-9.2$ & $6.3,4.2-7.0$ & $6.3,4.1-8.9$ \\
\hline DCSI, n (\%) & $1.44 \pm 1.46$ & 0 & $1.14 \pm 0.36$ & $3.05 \pm 1.19$ \\
\hline \multicolumn{5}{|c|}{ Comorbidity, n (\%) } \\
\hline Hypertension & $18,657(66.94)$ & $5164(56.56)$ & $5914(65.60)$ & $7579(77.93)$ \\
\hline Dyslipidemia & $20,225(72.57)$ & 5760 (63.09) & $6529(72.42)$ & $7936(81.60)$ \\
\hline Stroke & 2485 (8.92) & - & $423(4.69)$ & $2062(21.20)$ \\
\hline Myocardial infarction & $566(2.03)$ & - & $172(1.91)$ & $394(4.05)$ \\
\hline \multicolumn{5}{|l|}{ Antidiabetic drug adherence } \\
\hline Mean $\pm S D$ & $77.86 \pm 28.14$ & $76.26 \pm 28.54$ & $77.86 \pm 27.99$ & $79.36 \pm 27.81$ \\
\hline Median, IQR & $90.41,66.84-90.41$ & $90.13,65.75-98.63$ & $98.63,66.02-90.41$ & $90.41,71.50-98.63$ \\
\hline \multicolumn{5}{|c|}{ Medications, n (\%) } \\
\hline \multicolumn{5}{|l|}{ Antidiabetics } \\
\hline Metformin & $19,526(70.06)$ & $6418(70.30)$ & $6403(71.03)$ & 6705 (68.94) \\
\hline Sulfonylurea & $14,945(53.62)$ & $4989(54.64)$ & $4774(52.96)$ & $5182(53.28)$ \\
\hline DPP4-I & $4314(15.48)$ & $1365(14.95)$ & $1439(15.96)$ & $1965(20.20)$ \\
\hline Thiazolidinedione & $1703(6.11)$ & $483(5.29)$ & $531(5.89)$ & $689(7.08)$ \\
\hline Insulin & $715(2.57)$ & $113(1.24)$ & $156(1.73)$ & $446(4.59)$ \\
\hline \multicolumn{5}{|l|}{ Cardiovascular agents } \\
\hline Aspirin & $8791(31.54)$ & $1761(19.29)$ & $2803(31.09)$ & $4227(43.46)$ \\
\hline Clopidogrel & $1754(6.29)$ & $31(0.34)$ & $462(5.12)$ & $1261(12.97)$ \\
\hline Cilostazol & $1068(3.83)$ & $72(0.79)$ & $244(2.71)$ & $752(7.73)$ \\
\hline Sarpogrelate & $726(2.60)$ & $58(0.64)$ & $167(1.85)$ & $501(5.15)$ \\
\hline ACEI/ARB & $13,325(47.81)$ & $3534(38.71)$ & $4212(46.72)$ & $5579(57.36)$ \\
\hline DHPCCB & $11,336(40.67)$ & $3270(35.82)$ & $3594(39.87)$ & $4472(45.98)$ \\
\hline Statin & $12,966(46.52)$ & 3556 (38.95) & 4081 (45.27) & 5329 (54.79) \\
\hline
\end{tabular}

Study subject's characters were not normal distribution (Normality test - Kolmogorov-Smirnov)

Per oral drug use history is prescribed for more than 90 days in the previous year at 2 years after diagnosis T2DM

Abbreviation: CCI Charlson comorbidity index, DCSI diabetes complication severity index, DPP4-I dipeptidyl peptidase-4 inhibitor, ACEI/ARB angiotensin-1 converting enzyme Inhibitor/angiotensin-2 receptor blocker, $D H P C C B$ dihydropyridine-calcium channel blocker

\section{All-cause hospitalization}

A total of $14,297(51.30 \%)$ of the 27,871 patients were admitted to the hospital with a frequency of $3.27 \pm 5.0$. The mean frequency of hospitalization during the follow-up period was $2.96 \pm 5.69$ in patients without complications, $3.15 \pm 4.57$ with one complication, and $3.59 \pm 4.78$ with two or more complications. The average duration of hospitalization was 54.94 days in patients 
Table 2 New onset complications from 2 years after T2DM diagnosis to the end of follow up period

\begin{tabular}{|c|c|c|c|c|c|c|c|c|}
\hline \multirow{2}{*}{$\begin{array}{l}\text { Number of } \\
\text { complications }\end{array}$} & \multirow{2}{*}{$\begin{array}{l}\text { Number } \\
\text { of } \\
\text { patients, } \\
\mathrm{n}(\%)\end{array}$} & \multicolumn{7}{|c|}{ Category of complications, n (\%) } \\
\hline & & Nephropathy & Neuropathy & Retinopathy & $\begin{array}{l}\text { Cerebrovascular } \\
\text { disease }\end{array}$ & $\begin{array}{l}\text { Cardiovascular } \\
\text { disease }\end{array}$ & $\begin{array}{l}\text { Peripheral vascular } \\
\text { disease }\end{array}$ & $\begin{array}{l}\text { Acute metabolic } \\
\text { complications }\end{array}$ \\
\hline 1 & $\begin{array}{l}7248 \\
(39.52)\end{array}$ & $837(4.56)$ & $\begin{array}{l}2204 \\
(12.02)\end{array}$ & $1667(9.09)$ & $269(1.47)$ & $1410(7.69)$ & $823(4.49)$ & $38(0.21)$ \\
\hline 2 & $\begin{array}{l}5232 \\
(28.53)\end{array}$ & $1195(6.52)$ & $\begin{array}{l}2954 \\
(16.11)\end{array}$ & $\begin{array}{l}2120 \\
(11.56)\end{array}$ & $633(3.45)$ & $2095(11.42)$ & $1411(7.69)$ & $56(0.31)$ \\
\hline 3 & $\begin{array}{l}3250 \\
(17.72)\end{array}$ & $1203(6.56)$ & $\begin{array}{l}2401 \\
(13.09)\end{array}$ & $1804(9.84)$ & $814(4.44)$ & $2015(10.99)$ & $1450(7.91)$ & $63(0.34)$ \\
\hline 4 & $\begin{array}{l}1718 \\
(4.00)\end{array}$ & $924(5.04)$ & $1509(8.23)$ & $1215(6.63)$ & $685(2.46)$ & $1372(7.48)$ & $1101(6.00)$ & $66(0.36)$ \\
\hline 5 & $\begin{array}{l}733 \\
(2.63)\end{array}$ & 556 (3.0.) & $688(3.75)$ & $632(3.45)$ & $448(1.61)$ & $688(3.75)$ & $609(3.32)$ & $44(0.24)$ \\
\hline 6 & $\begin{array}{l}150 \\
(0.82)\end{array}$ & $149(0.81)$ & $149(0.81)$ & $149(0.81)$ & $140(0.50)$ & $150(0.82)$ & $146(0.80)$ & $17(0.09)$ \\
\hline 7 & $8(0.004)$ & $8(0.04)$ & $8(0.04)$ & $8(0.04)$ & $8(0.03)$ & $8(0.4$ & $8(0.04)$ & $8(0.04)$ \\
\hline Total & $\begin{array}{l}18,339 \\
(100)\end{array}$ & $4872(26.57)$ & $\begin{array}{l}9913 \\
(54.05)\end{array}$ & $\begin{array}{l}7595 \\
(41.41)\end{array}$ & $2997(10.75)$ & $7738(42.19)$ & $5548(30.25)$ & $292(1.59)$ \\
\hline
\end{tabular}

Table 3 Relative risk of new onset diabetic complications by patient characteristics

\begin{tabular}{ll}
\hline Characteristics & Composite complications RR (95\% CI) \\
\hline Age & $1.006(1.005-1.007)^{\mathrm{a}}$ \\
Men (Ref. women) & $0.93(0.92-0.95)^{\mathrm{a}}$ \\
CCI & $1.018(1.013-1.023)^{\mathrm{a}}$ \\
Baseline DCSI & $1.26(1.25-1.27)^{\mathrm{a}}$ \\
Insulin & $1.07(1.03-1.11)^{\mathrm{a}}$ \\
Aspirin & $1.07(1.06-1.09)^{\mathrm{a}}$ \\
Clopidogrel & $0.96(0.94-0.98)^{\mathrm{a}}$ \\
Sarpogrelate & $1.00(0.97-1.02)$ \\
Cilostazol & $0.99(0.95-1.03)$ \\
ACEI/ARB & $0.99(0.98-1.01)$ \\
Statin & $0.92(0.91-0.93)^{\mathrm{a}}$ \\
Number of antidiabetics & \\
1 & Reference \\
2 & $1.01(1.00-1.03)$ \\
3 + & $1.13(1.10-1.17)^{\mathrm{a}}$ \\
Antidiabetics therapy & \\
Mono therapy & \\
Metformin &
\end{tabular}

Abbreviation: $\mathrm{CCl}$ Charlson comorbidity index score, $A C E I / A R B$ angiotensin-1 converting enzyme Inhibitor/angiotensin-2 receptor blocker, DPP4-I dipeptidyl peptidase-4 inhibitor

${ }^{a}$ statistically significant without complications, 76.40 days with one complication, and 106 days with two or more complications (Supplement Table 4).

The adjusted RR of hospitalization was 1.06 (95\% CI 1.01-1.11) when DCSI was 1 , and it increased to 1.34 (95\% CI 1.23-1.47) when DCSI was $\geq 5$ compared with when DCSI was 0 as the reference (Table 4 , Supplement Table 5).

\section{All-cause mortality}

Among the 27,871 patients, 2302 (8.26\%) died because of all causes. Overall, 490 (5.37\%) of the 9130 patients without complications, 659 (7.31\%) of the 9015 patients with one complication, and 1153 (11.85\%) of the 9726 patients with two or more complications died (Supplement Table 4). The ROC curve showed that DCSI was a useful indicator of mortality (Supplement figure 2). As the number of diabetes complications increased, the survival rate of patients decreased significantly (Fig. 2). The adjusted hazard ratio of mortality increased to 1.05 (95\% CI 0.93-1.19) when DCSI was 1 and 1.87 (95\% CI 1.602.19) when DCSI was $\geq 5$ compared with when DCSI was 0 as the reference (Table 4, Supplement Table 6).

\section{Discussion}

This study showed the clinical significance that DCSI including the number and severity of complications at 2 years after T2DM diagnosis was associated with mortality and hospitalization based on the real world data for a study period from 2002 to 2015 . The hazard model and survival analysis using DCSI could be utilized for the stratification of risks for improving the strategy of medical care to prevent adverse events associated with DM complications. Patients with complications increased to 
Table 4 Relative risk of hospitalization and hazard ratio of mortality

\begin{tabular}{|c|c|c|}
\hline Characteristics & Hospitalization adjusted RR $(95 \% \mathrm{Cl})$ & Mortality adjusted $\mathrm{HR}^{\mathrm{a}}(95 \% \mathrm{Cl})$ \\
\hline Age & $1.009(1.008-1.011)$ & $1.093(1.088-1.097)$ \\
\hline Men (Ref. women) & $0.94(0.90-0.97)$ & $1.80(1.65-1.96)$ \\
\hline Insulin use & $1.91(1.81-2.02)$ & $2.83(2.52-3.17)$ \\
\hline Diabetic complications severity index (linear) & $1.04(1.03-1.06)$ & $1.13(1.11-1.16)$ \\
\hline \multicolumn{3}{|l|}{ DCSI (categorical) } \\
\hline 0 & Reference & Reference \\
\hline 1 & $1.06(1.01-1.11)$ & $1.05(0.93-1.19)$ \\
\hline 2 & $1.10(1.04-1.16)$ & $1.12(0.98-1.27)$ \\
\hline 3 & $1.11(1.03-1.18)$ & $1.34(1.17-1.54)$ \\
\hline 4 & $1.21(1.12-1.32)$ & $1.76(1.51-2.05)$ \\
\hline $5+$ & $1.34(1.23-1.47)$ & $1.87(1.60-2.19)$ \\
\hline \multicolumn{3}{|l|}{ Number of complications (categorical) } \\
\hline 0 & Reference & Reference \\
\hline 1 & $1.06(1.01-1.11)$ & $1.10(0.98-1.24)$ \\
\hline 2 & $1.10(1.04-1.16)$ & $1.29(1.14-1.46)$ \\
\hline 3 & $1.16(1.08-1.24)$ & $1.45(1.26-1.66)$ \\
\hline 4 & $1.22(1.11-1.34)$ & $1.57(1.31-1.89)$ \\
\hline $5+$ & $1.36(1.18-1.57)$ & $1.65(1.24-2.20)$ \\
\hline
\end{tabular}

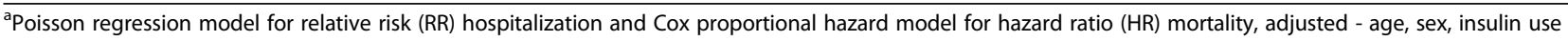

$87 \%$ and the number and severity of complications increased as the duration of diabetes was longer during a mean follow-up period of 6.56 years. Approximately $50 \%$ of the complications occurred within 2 years of T2DM diagnosis (supplement figure 1). The higher the DCSI and number of complications were, the more the risk of mortality and hospitalization increased (Supplement Table 4-6) As the number of complications increases, the disease burden, mortality, and medical costs also increase $[15,17]$. The management of diabetes complications as well as blood glucose control is crucial in diabetic patients $[9,12,22]$. Studies have reported on antidiabetic drugs, such as DPP4I and SGLT2I, which reduce or delay the occurrence of diabetes complications [23-28]. Furthermore, studies have evaluated the effects of cilostazol, sarpogrelate, and antiplatelets in preventing or delaying diabetic nephropathy [29, 30]. Statin has been recommended for primary and secondary prevention of cardiovascular and cerebrovascular disease with LDL-c levels below $100 \mathrm{mg} / \mathrm{dL}$ even in patients with type 2 diabetes [31]. The prevalence of dyslipidemia was $34.9 \%$ in patients with DM in the Korean population [32] and $72.6 \%$ in our study patients who had been strictly defined with T2DM diagnosis and with antidiabetic medications. They tried first with lifestyle modification followed by drug therapy. The use of statin therapy at the index date was $46.5 \%$ in our study patients which have been acceptable at the early stage of $\mathrm{DM}$ as a usual medical practice with health insurance reimbursement criteria in Korea. The risk of new DM complications was lower RR of 0.71 (95\% CI, 0.69-0.73) in patients with statins in this study which implied to encourage statin use in the early stage within 2 years of T2DM diagnosis in Korea.

Young et al. analyzed diabetes complications in patients with DM. The patient group included both type 1 and type $2 \mathrm{DM}$ and was analyzed for the risk of mortality until the end of the follow-up period of 4 years from 2001 to 2005. The risk of mortality did not increase significantly in patients with one complication but increased by 1.9 times in two complications, and 7.18 times in more than 5 complications. Similar results were obtained when DCSI was used instead of the number of diabetes complications [14]. Compared with a previous study, the present study used a sample cohort of the Korean National Health Insurance Claim database, analyzed the risk of mortality based on the number and severity of the complications at 2 years postdiagnosis in patients with new T2DM. The follow-up period after the index date of 2 years after the T2DM diagnosis was longer than that reported in a previous study. The duration of complications postdiagnosis was 2 years postdiagnosis for predicting the mortality in the patients, and the subsequent follow-up period ranged from a minimum of 2 years to a maximum of 12 years. To minimize the effects of death due to reasons other than diabetes complications, patients with cancer, severe liver failure, and severe renal dysfunction requiring dialysis or kidney 


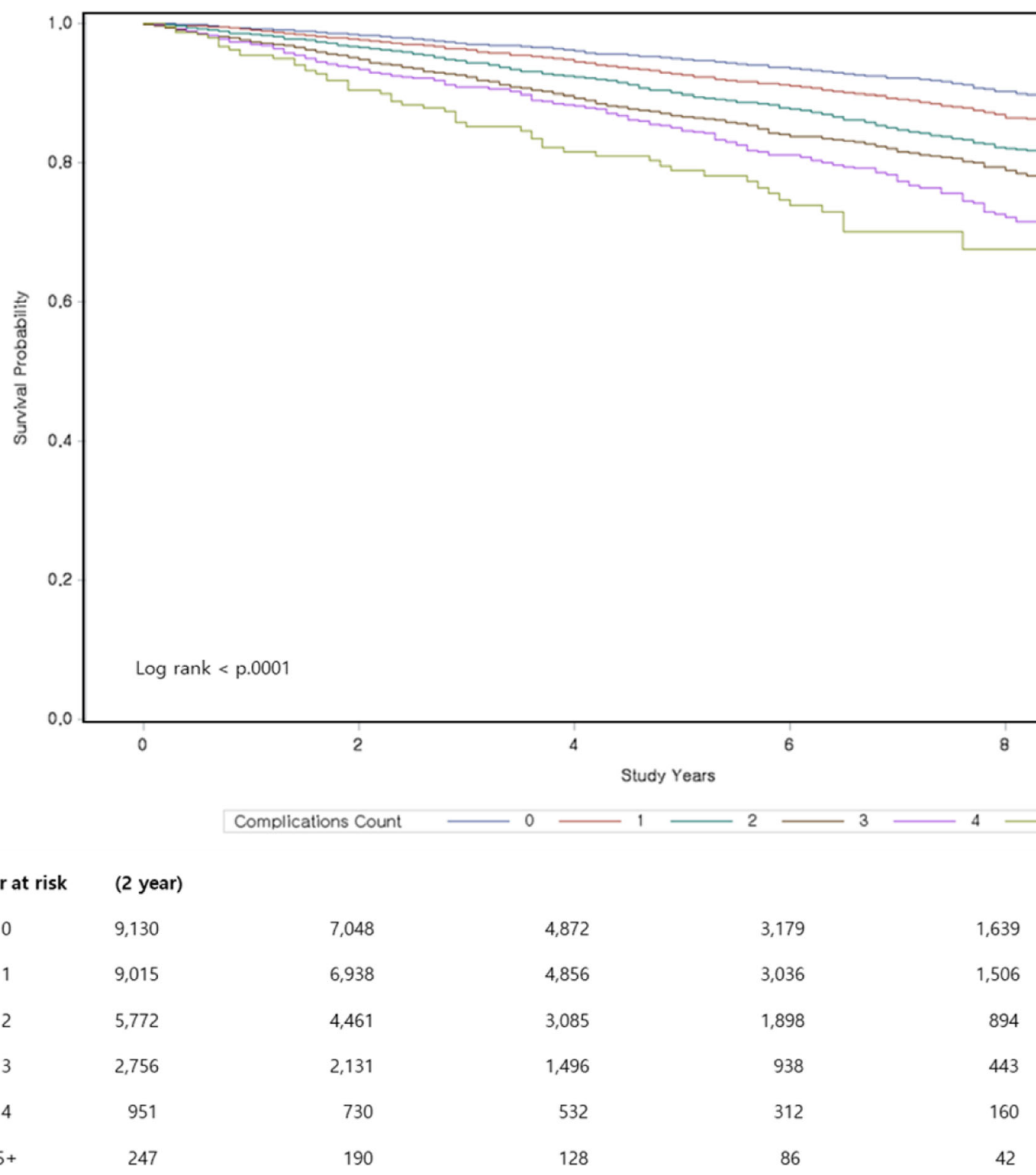

Fig. 2 Kaplan-Meier survival curves stratified by number of complications for follow up period

transplantation were excluded from the study. Although the previous and the present studies were different in terms of the inclusion criteria, exclusion criteria, and follow up period, it was confirmed that the risk of mortality increased significantly as the number and severity of complications increased compared with the patients with no or fewer diabetes complications.

The present study used the National Health Insurance Claim database which is based on the available claim and demographics data held by the National Health Insurance Corporation (NHIC) and is representative of the Korean population. This study was a retrospective cohort design, which reflected the process of diabetes diagnosis and treatment in the real world clinical practice. The study design included a postdiagnosis period of 2 years as the run-in period before the index date. The complications at 2-year postdiagnosis as the index date were the baseline clinical information associated with the mortality and hospitalization during the follow-up period. The present study also analyzed the factors associated with the complications, which included comorbidity, type of antidiabetic drugs, the pattern of pharmacotherapy, and concomitant medications. The risk of hospitalization or mortality was assessed by levels of zero to 5 or more DCSI, which reflects the number and severity of diabetes complications. Diabetes patients 
can be stratified according to their severity of morbidity through indicators such as DCSI with HbA1C or blood glucose levels. The utilization of DCSI in assessing patients with DM can improve the strategy in medical care and medication therapy management with the intensified consultation and proper reimbursement for the services. In the case of chronic diseases such as diabetes, medical benefits or services need to be differentiated according to the severity of complications. More medical insurance benefits could be provided for patients with severe diseases, which would save the direct or indirect medical costs. Clinical excellence in the medical care of DM patients would use efficiently the medical resources. The National Health Insurance System (NHIS) is operated by a single insurer for the entire nation with universal insurance and a mandatory service as a social security system in Korea. The public pays health insurance premiums to the NHIC by differentiating them according to income. When you see a doctor in a hospital or take a prescription drug from a pharmacy, you pay $30 \%$ as a copayment and a medical institution receives a $70 \%$ national contribution of the medical bill claims.

The present study had some limitations. The NHID data comprises health insurance claim data as well as the 2-year regular health examination data. This study could not include clinical laboratory tests related to the complications. The DM complications could not be analyzed on the basis of the clinical test results for glycosylated hemoglobin, blood glucose, blood pressure, lipid, and glomerular filtration rate because the NHID is not an electronic medical record of hospital patients. The health examination data included in the NHID is the result of regular check-ups every 2 years, independent of medical care in a hospital. However, the concurrent medications and diseases were included in the analyses instead of the laboratory tests to evaluate the effects of the clinical factors on the incidence of complications and the risk of mortality or hospitalization. Besides, we could not use the information on weight, diet, genetic factors, smoking status, and vaccination, which were the risk factors for diabetes complications. In the present study, the occurrence of complications was identified using only diagnostic codes comprising 55 subcategories of 7 categories, which reflected the diabetes complications evaluated in a previous study [14] as much as possible. The complications were measured at 2 years after T2DM diagnosis to match with the duration of diabetes among the study subjects with a relatively longer follow-up out of the study period. The baseline complications at 5 or 10 years after T2DM diagnosis would also be interesting for evaluating the risks of mortality and hospitalization for a shorter follow-up period.

\section{Conclusions}

In this retrospective cohort study using the claim data of the National Health Insurance Sample Cohort as the real world data, DCSI including the number and severity of DM complications showed the association of complications with mortality and hospitalization in patients with diabetes. The incidence of complications was different based on coexisting diseases, hypoglycemic agents, and concomitant medications. DCSI can be utilized to assess and care appropriately for patients with DM in addition to hemoglobin A1c and blood glucose level.

\section{Supplementary information}

Supplementary information accompanies this paper at https://doi.org/10. 1186/s12902-020-00605-5.

Additional file 1 : Supplement Table 1. Diabetes complications severity index and list of complications developed from KCD-7 code. Supplement Table 2. Drug use patterns in patients without and with new onset complications from 2 years after DM diagnosis to the end of follow up period. Supplement Table 3. Number and category of complications at 2 years after T2DM diagnosis and the end of the follow-up period. Supplement Table 4. All-cause mortality and hospitalization. Supplement Table 5. Relative risk of hospitalization with Poisson regression model. Supplement Table 6. Hazard ratio of mortality with Cox proportional hazard model. Supplement figure 1. Changes in category of diabetic complications according to duration of diabetes mellitus (A), Changes in number of diabetic complications according to duration of diabetes mellitus (B). Supplement figure 2. Receiver operating charac teristics (ROC) curves comparing the diabetic complications severity index (DCSI) with complications count (blue). The lines of DCSI (dotted red) and DCSI linear (dotted green) were overlapped.

\section{Abbreviations}

T2DM: Type 2 diabetes mellitus; NHIS-NSC: National Health Insurance Service-National Sample Cohort; NHID: National Health Insurance Database; DCSI: Diabetes complications severity index; SU: Sulfonylurea;

DPP4I: Dipeptidyl peptidase-4 inhibitor; ACEl/ARB: Angiotensin-1 converting enzyme inhibitor/angiotensin-2 receptor blocker; DHP-CCB: Dihydropyridinecalcium channel blocker

\section{Acknowledgments \\ The authors would like to thank Enago (www.enago.co.kr) to review the article for English.}

\section{Authors' contributions}

$H Y, E C, S L$ analyzed and interpreted the cohort data regarding the demographics, antidiabetic drug use, complications, mortality, and hospitalization. HY and SL performed to design the study and were a major contributor in writing the manuscript. All authors read and approved the final manuscript.

\section{Funding}

This study was supported by Ajou University grants (S2019G000100302, S2019G000100494) which had no role in the design of the study and collection, analysis, and interpretation of data, and in writing the manuscript.

\section{Availability of data and materials}

The population-based cohort data that support the findings of this study are available from the Korean National Health Insurance Service (NHIS) but restrictions apply to the availability of these data, which were used under license for the current study with online access to the Big Data Center server of NHIS through a designated computer and so are not publicly available. Only results of analysis only could be taken out and analysis could be repeated once for validation on request by authors. 


\section{Ethics approval and consent to participate}

The study was approved by the Institutional Review Board of Ajou University Hospital (AJIRB-MEDMDB-15-503) and the Korean National Health Insurance Service (REQ0000018562). The informed consent of study subjects was waved due to the characteristics of data with de-identification of personal information of claim data and analysis with online access to the Big Data Center server of the National Health Insurance Service in Korea.

\section{Consent for publication}

Not applicable.

\section{Competing interests}

The authors declare that they have no competing interests.

Received: 9 January 2020 Accepted: 31 July 2020

Published online: 10 August 2020

\section{References}

1. Cho N, Shaw J, Karuranga S, Huang Y, da Rocha FJ, Ohlrogge A, et al. IDF diabetes atlas: global estimates of diabetes prevalence for 2017 and projections for 2045. Diabetes Res Clin Pract. 2018;138:271-81.

2. Serah W, Richard S, Gojka G, Hilary K, Anders G. Global prevalence of diabetes: estimates for the year 2000 and projections for 2030. Diabetes Care. 2004;27:1047-53.

3. Di Pino A, Mangiafico S, Urbano F, Scicali R, Scandura S, D'Agate V, et al. $\mathrm{HbA1c}$ identifies subjects with prediabetes and subclinical left ventricular diastolic dysfunction. J Clin Endocrinol Metab. 2017;102(10):3756-64.

4. Di Pino A, Urbano F, Scicali R, Di Mauro S, Filippello A, Scamporrino A, et al. $1 \mathrm{~h}$ Postload Glycemia is associated with low endogenous secretory receptor for advanced Glycation end product levels and early markers of cardiovascular disease. Cells. 2019;8(8):910.

5. Fiorentino TV, Succurro E, Andreozzi F, Sciacqua A, Perticone F, Sesti G. Onehour post-load hyperglycemia combined with $\mathrm{HbA1c}$ identifies individuals with higher risk of cardiovascular diseases: cross-sectional data from the CATAMERI study. Diabetes Metab Res. 2019;35(2):e3096.

6. Scicali R, Giral P, Gallo A, Di Pino A, Rabuazzo AM, Purrello F, et al. HbA1c increase is associated with higher coronary and peripheral atherosclerotic burden in non diabetic patients. Atherosclerosis. 2016;255:102-8.

7. American Diabetes Association. 6. Glycemic Targets: Standards of Medical Care in Diabetes-2018. Diab Care. 2018:41(Suppl 1):S55-64.

8. American Diabetes Association. 8. Pharmacologic Approaches to Glycemic Treatment: Standards of Medical Care in Diabetes-2018. Diab Care. 2018; 41(Suppl 1):S73-85.

9. American Diabetes Association. 10. Microvascular Complications and Foot Care: Standards of Medical Care in Diabetes-2018. Diabetes Care. 2018; 41(Suppl 1):S105-18.

10. Whelton PK, Carey RM, Aronow WS, Casey DE, Collins KJ, Himmelfarb CD, et al. 2017 ACC/AHA/AAPA/ABC/ACPM/AGS/APhA/ASH/ASPC/NMA/PCNA guideline for the prevention, detection, evaluation, and management of high blood pressure in adults: a report of the American College of Cardiology/American Heart Association task force on clinical practice guidelines. J Am Coll Cardiol. 2018;71(19):e127-248.

11. Grundy SM, Stone NJ, Bailey AL, Beam C, Birtcher KK, Blumenthal RS, et al. 2018 AHA/ACC/AACVPR/AAPA/ABC/ACPM/ADA/AGS/APhA/ASPC/NLA/ PCNA guideline on the management of blood cholesterol: a report of the American College of Cardiology/American Heart Association task force on clinical practice guidelines. J Am Coll Cardiol. 2019;73(24):e285-350.

12. American Diabetes Association. 9. Cardiovascular Disease and Risk Management: Standards of Medical Care in Diabetes-2018. Diab Care. 2018; 41(Suppl 1):S86-S104.

13. Emerging Risk Factors Collaboration. Diabetes mellitus, fasting blood glucose concentration, and risk of vascular disease: a collaborative metaanalysis of 102 prospective studies. Lancet. 2010;375(9733):2215-22.

14. Young BA, Lin E, Von Korff M, Simon G, Ciechanowski P, Ludman EJ, et al. Diabetes complications severity index and risk of mortality, hospitalization, and healthcare utilization. Am J Manag Care. 2008;14(1):15-23.

15. Hex N, Bartlett C, Wright D, Taylor M, Varley D. Estimating the current and future costs of type 1 and type 2 diabetes in the UK, including direct health costs and indirect societal and productivity costs. Diab Med. 2012;29(7):855-62.
16. Yoon J, Oh I, Seo H, Kim E, Gong Y, Ock M, et al. Disability-adjusted life years for 313 diseases and injuries: the 2012 Korean burden of disease study. J Korean Med Sci. 2016;31(Suppl 2):S146-57.

17. Rosenzweig $\mathrm{J}$, Weinger $K$, Poirier-Solomon L, Rushton M. Use of a disease severity index for evaluation of healthcare costs and management of comorbidities of patients with diabetes mellitus. Am J Manag Care. 2002; 8(11):950-8.

18. Selby JV, Karter AJ, Ackerson LM, Ferrara A, Liu J. Developing a prediction rule from automated clinical databases to identify high-risk patients in a large population with diabetes. Diabetes Care. 2001;24(9):1547-55.

19. Kwon S. Payment system reform for health care providers in Korea. Health Policy Plan. 2003;18(1):84-92.

20. Lee J, Lee JS, Park S, Shin SA, Kim K. Cohort profile: the national health insurance service-national sample cohort (NHIS-NSC), South Korea. Int J Epidemiol. 2016:46(2):e15.

21. Sundararajan V, Henderson T, Perry C, Muggivan A, Quan H, Ghali WA. New ICD-10 version of the Charlson comorbidity index predicted in-hospital mortality. J Clin Epidemiol. 2004;57(12):1288-94.

22. Forbes JM, Cooper ME. Mechanisms of diabetic complications. Physiol Rev. 2013;93(1):137-88

23. Perkovic V, Jardine MJ, Neal B, Bompoint S, Heerspink HJ, Charytan DM, et al. Canagliflozin and renal outcomes in type 2 diabetes and nephropathy. N Engl J Med. 2019;380(24):2295-306.

24. Wanner C, Inzucchi SE, Lachin JM, Fitchett D, von Eynatten M, Mattheus M, et al. Empagliflozin and progression of kidney disease in type 2 diabetes. $\mathrm{N}$ Engl J Med. 2016:375(4):323-34

25. Neal B, Perkovic V, Mahaffey KW, De Zeeuw D, Fulcher G, Erondu N, et al. Canagliflozin and cardiovascular and renal events in type 2 diabetes. N Engl J Med. 2017;377(7):644-57.

26. Mann JF, Ørsted DD, Brown-Frandsen K, Marso SP, Poulter NR, Rasmussen S, et al. Liraglutide and renal outcomes in type 2 diabetes. N Engl J Med. 2017;377(9):839-48.

27. Marso SP, Daniels GH, Brown-Frandsen K, Kristensen P, Mann JF, Nauck MA, et al. Liraglutide and cardiovascular outcomes in type 2 diabetes. N Engl J Med. 2016:375(4):311-22.

28. Marso SP, Bain SC, Consoli A, Eliaschewitz FG, Jódar E, Leiter LA, et al. Semaglutide and cardiovascular outcomes in patients with type 2 diabetes. N Engl J Med. 2016;375(19):1834-44.

29. Yoo H, Park I, Kim DJ, Lee S. Effects of sarpogrelate on microvascular complications with type 2 diabetes. Int I Clin Pharm. Int J Clin Pharm. 2019; 41(2):563-73.

30. Noh Y, Lee J, Shin S, Park I, Bae SK, Oh E, et al. Effects of cilostazol and renin-angiotensin system (RAS) blockers on the renal disease progression of Korean patients: a retrospective cohort study. Int J Clin Pharm. 2018;40(1): 160-8.

31. Scicali R, Di Pino A, Ferrara V, Urbano F, Piro S, Rabuazzo AM, et al. New treatment options for lipid-lowering therapy in subjects with type 2 diabetes. Acta Diabetol. 2018:55(3):209-18.

32. Kim B, Won JC, Lee JH, Kim H, Park JH, Ha KH, et al. Diabetes fact sheets in Korea, 2018: an appraisal of current status. Diab Metab J. 2019:43(4):487-94.

\section{Publisher's Note}

Springer Nature remains neutral with regard to jurisdictional claims in published maps and institutional affiliations.

Ready to submit your research? Choose BMC and benefit from:

- fast, convenient online submission

- thorough peer review by experienced researchers in your field

- rapid publication on acceptance

- support for research data, including large and complex data types

- gold Open Access which fosters wider collaboration and increased citations

- maximum visibility for your research: over $100 \mathrm{M}$ website views per year

At BMC, research is always in progress.

Learn more biomedcentral.com/submission 